\title{
RESEÑA
}

\section{Psicología para el profesorado de Educación Secundaria y Bachillerato}

\author{
Carlos Martín Bravo \\ José I. Navarro Guzmán \\ (Coordinadores) \\ Editorial Pirámide \\ Año: 2011
}

"Psicología para el profesorado de Educación Secundaria y Bachillerato" es un manual universitario de enorme interés que logra de forma armónica la difusión de la ciencia psicológica entre los futuros - y actuales- docentes de enseñanza secundaria y bachillerato. Para ello, el manual presenta, en primer lugar, una lograda selección de aquellos contenidos más apropiados en el desarrollo de competencias, que señala el Espacio Europeo de Educación Superior (EEES), para este tipo de profesorado; como son: "cerebro, adolescencias y educación", "desarrollo del pensamiento en la adolescencia", "estrategias de aprendizaje: evaluación y enseñanza en secundaria", o "habilidades docentes básicas"... por citar algunos de los capítulos.

En segundo lugar, los autores, profesores de las universidades de Oviedo, Valladolid, Huelva y Cádiz han realizado un loable esfuerzo de narrativa clara que, sin perder rigor, logran que la lectura sea fácil y fluida. En esa línea se sitúan los continuos ejemplos, esquemas y mapas conceptuales que ayudan al estudioso de otros campos del saber a entender la aportación de la psicología a la actividad práctica de los procesos de enseñar y aprender presentes en los distintos centros educativos: secundaria, bachillerato, formación profesional o las escuelas oficiales de idiomas.

En tercer lugar, el manual se hace eco de un espacio reservado a una serie de actividades prácticas que aparecen al final de cada uno de los ocho capítulos que forman el total de la obra que comentamos. Del mismo modo que se ha dotado de referencias vinculadas a "videos cortos" que ayudan a comprender y manejar de forma reflexiva aquellos contenidos que se prestan, por su naturaleza, a generar debates con los alumnos en clase. 
Por último, los diferentes autores se han preocupado de la elaboración de un glosario de ayuda a los lectores que son de distintas procedencias y que, por ello, se supone se encuentran en el manejo y dominio de un campo conceptual distinto al de la psicología. La obra, en fin, ofrece un vigoroso esfuerzo de actualización bibliográfica, siendo este aspecto digno de remarcar. En definitiva, solo queda, agradecer a los coordinadores y coautores de esta obra por su esfuerzo en abrir y/o estimular una línea de trabajo poco reconocida en nuestro país. Pues de la misma forma que se estimulan las publicaciones de impacto, debemos, también, prestar atención a la elaboración de manuales universitarios de calidad e impacto y, éste, es uno de ellos.

Dr. Fernando Lara

Profesor de Psicología de la Universidad de Castilla-León Burgos (España) 